Article

\title{
Synthesis and Biological Evaluation of Novel Furozan-Based Nitric Oxide-Releasing Derivatives of Oridonin as Potential Anti-Tumor Agents
}

\section{Dahong Li ${ }^{1,2, \dagger}$, Lei Wang ${ }^{1,3, \dagger}$, Hao Cai ${ }^{1}$, Yihua Zhang ${ }^{2,3, *}$ and Jinyi Xu ${ }^{1,2, *}$}

1 Department of Medicinal Chemistry, China Pharmaceutical University, 24 Tongjia Xiang, Nanjing 210009, China

2 State Key Laboratory of Natural Medicines, China Pharmaceutical University, 24 Tongjia Xiang, Nanjing 210009, China

3 Center of Drug Discovery, China Pharmaceutical University, 24 Tongjia Xiang, Nanjing 210009, China

$\dagger$ These authors contributed equally to this work.

* Authors to whom correspondence should be addressed; E-Mails: zyhtgd@sohu.com (Y.Z.); jinyixu@china.com (J.X.); Tel.: +86-25-8327-1445 (J.X.); Fax: +86-25-8330-2827 (J.X.).

Received: 25 April 2012; in revised form: 8 June 2012 / Accepted: 12 June 2012 /

Published: 18 June 2012

\begin{abstract}
To search for novel nitric oxide (NO) releasing anti-tumor agents, a series of novel furoxan/oridonin hybrids were designed and synthesized. Firstly, the nitrate/nitrite levels in the cell lysates were tested by a Griess assay and the results showed that these furoxan-based NO-releasing derivatives could produce high levels of NO in vitro. Then the anti-proliferative activity of these hybrids against four human cancer cell lines was also determined, among which, $\mathbf{9 h}$ exhibited the most potential anti-tumor activity with $\mathrm{IC}_{50}$ values of $1.82 \mu \mathrm{M}$ against $\mathrm{K} 562,1.81 \mu \mathrm{M}$ against $\mathrm{MGC}-803$ and $0.86 \mu \mathrm{M}$ against Bel-7402, respectively. Preliminary structure-activity relationship was concluded based on the experimental data obtained. These results suggested that NO-donor/natural product hybrids may provide a promising approach for the discovery of novel anti-tumor agents.
\end{abstract}

Keywords: NO donor; oridonin; hybrid; anti-tumor agents; SAR 


\section{Introduction}

Nitric oxide, a special gaseous molecular, is a key mediator involved in many physiological and pathological processes [1,2]. High concentrations of NO and its metabolic derivatives can modify functional proteins, leading to cell cycle arrest and apoptosis, particularly in tumor cells [3-5]. Indeed, some synthesized NO-releasing compounds have shown cytotoxic activity against human carcinoma cells in vitro and inhibit the growth and metastasis of cancers in vivo [6-8]. So, the NO-based anti-cancer agents have been investigating for cancer therapy at clinic $[9,10]$. Furoxans represent one class of NO donors that can produce high levels of NO and exhibit strong anti-cancer activity [11,12]. In the previous work by our group, several classes of NO-releasing compounds have been reported, which possess strong anti-proliferative activity against human carcinoma cells in vitro, inhibition of cancer cells growth in vivo and the ability to increase sensitivity of Pgp-mediated multidrug resistance (MDR) in solid tumors, separately [13-17]. These results motivated us to further design some novel NO-donor/natural product hybrids.

Oridonin (1, see Figure 1) is a commercially available natural ent-kaurene diterpenoid that has recently attracted much attention because of its anti-tumor activity with a mechanism of inhibition effect on nuclear factor $\kappa B(N F-\kappa B)$ activation, induction of $G_{2} / M$ phase arrest and apoptosis [18]. Oridonin has been safely used for the treatment of hepatoma and promyelocytic leukemia in China for many years. In previous studies, we found that a series of novel 1-O- and 14-O-derivatives of oridonin exhibited stronger cytotoxicity against six cancer cell lines in vitro and some of them had stronger anti-tumor activity than the parent compound $\mathbf{1}$ and the positive control cyclophosphamide in mice with H22 liver tumor in vivo [19-21]. Hence, it may be a desired lead compound using for further design of novel furoxan-based NO-releasing derivatives for the development of anti-tumor agents. Therefore, a series of novel furozan-based nitric oxide-releasing derivatives of oridonin were designed and synthesized.

Figure 1. The structure and atom numbering of oridonin.

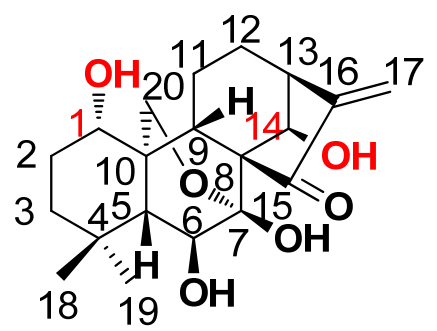

1

\section{Results and Discussion}

\subsection{Synthesis of Furoxan-Based NO Donor}

The substituted furoxans were prepared in five steps in the following way (Scheme 1). The starting material benzenethiol (2) was converted to 2-(phenylthio)acetic acid (4) by treatment with chloroacetic acid (3). Then, compound 4 was oxidized by $30 \% \mathrm{H}_{2} \mathrm{O}_{2}$ aqueous solution to give 2-(phenylsulfonyl) 
acetic acid (5) and fuming $\mathrm{HNO}_{3}$ was added to obtain diphenylsulfonylfuroxan (6), which was then converted to various monophenylsulfonylfuroxans $\mathbf{7 a - c}$ by treatment with the corresponding diol. Finally, anhydrides were added and furoxan-based NO donors $\mathbf{8 a}-\mathbf{i}$ were obtained.

Scheme 1. Synthesis of compounds 8a-i.
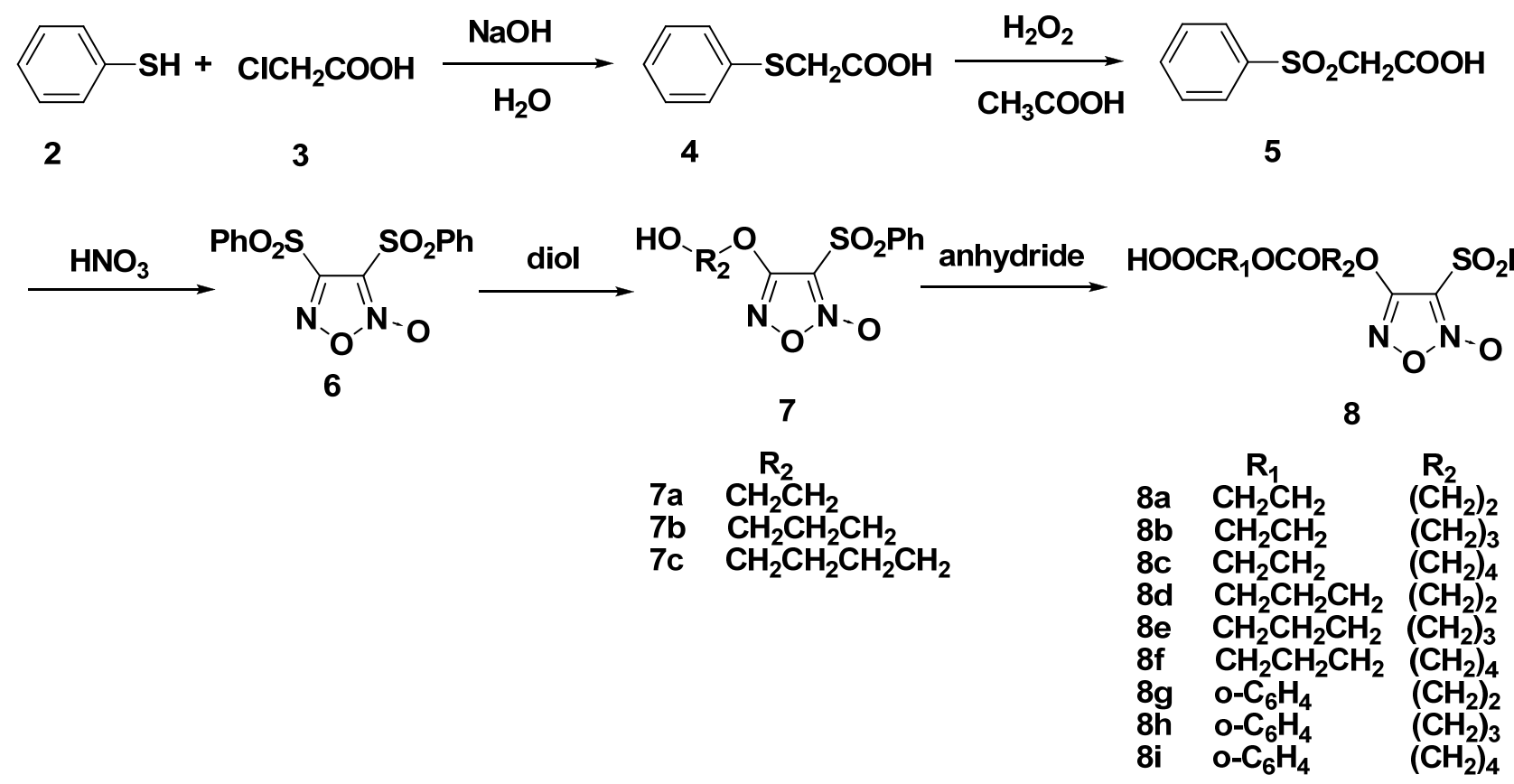

\subsection{Synthesis of Furoxan/Oridonin Hybrids}

The resulting furoxans $8 \mathbf{8}-\mathbf{i}$ were treated with oridonin to give the target compounds $9 \mathbf{a}-\mathbf{i}$, as shown in Scheme 2.

Scheme 2. Synthesis of compounds 9a-i.

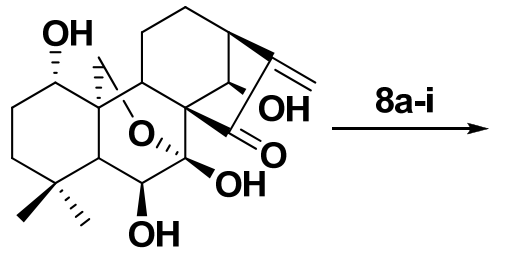

1

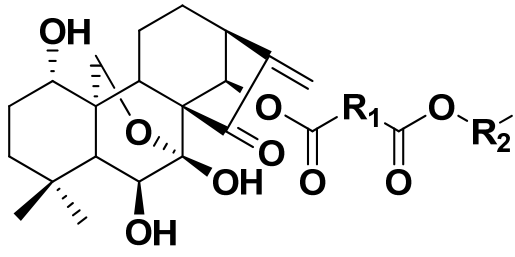

9

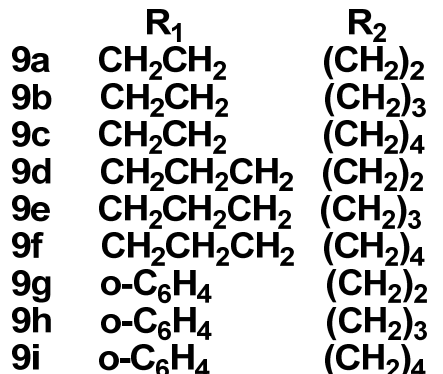

$\left(\mathrm{CH}_{2}\right)_{3}$

Treatment of oridonin with 2,2-dimethoxypropane (DMP) in the presence of $p$-toluenesulfonic acid $(\mathrm{TsOH})$ in acetone afforded 7,14-(1-methylethylene)-dioxyoridonin derivative 10. Compound 10 upon reaction with $\mathrm{Ac}_{2} \mathrm{O}$ /pyridine yielded 1-O-acetyl derivative 11. Deprotection of 11 with $\mathrm{AcOH}$ gave 1-O-acetyl-oridonin 12 in quantitative yield. Target compounds $\mathbf{1 3 a}-\mathbf{i}$ were prepared by reaction of $\mathbf{1 2}$ with furoxan-based NO donors $\mathbf{8 a}-\mathbf{i}$ in the presence of 4-dimethylaminopyridine/1-ethyl-3-(3dimethyllaminopropyl)carbodiimide hydrochloride (DMAP/EDCI) in $\mathrm{CH}_{2} \mathrm{Cl}_{2}$, as shown in Scheme 3. 
Scheme 3. Synthesis of compounds 13a-i.

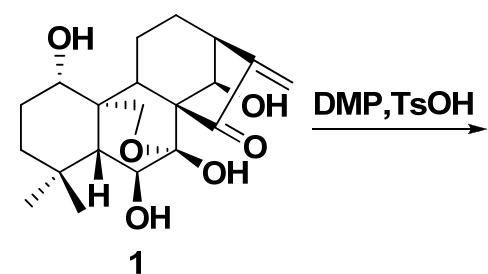

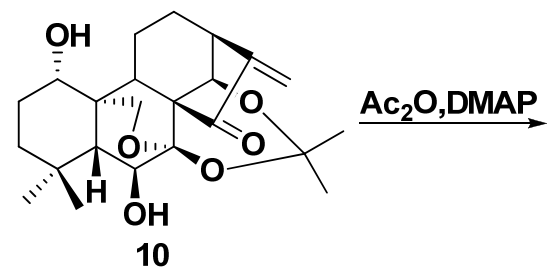

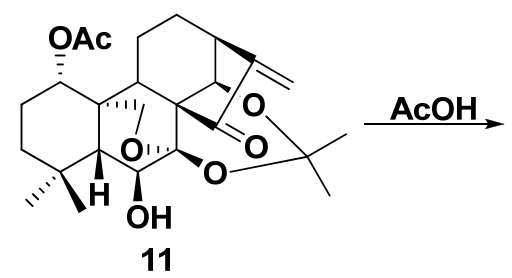

11

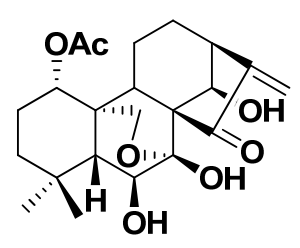

12

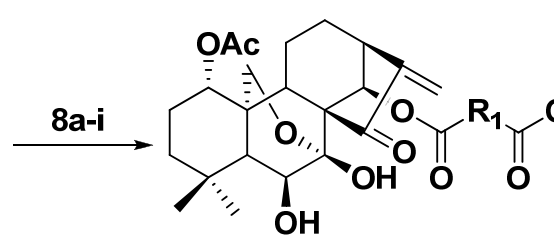

13

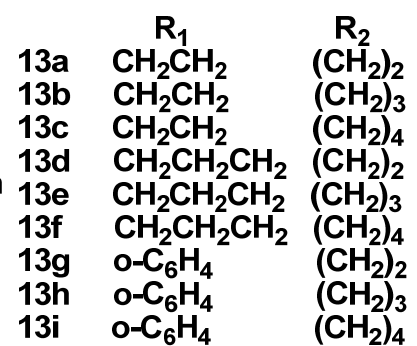

\subsection{NO-Releasing Test of Hybrids $\mathbf{9 a - i}$ and $\mathbf{1 3 a}-\mathbf{i}$ in Vitro}

The levels of nitrate/nitrite in the lysates of target compounds $9 \mathbf{a}-\mathbf{i}$ and $\mathbf{1 3 a} \mathbf{a}-\mathbf{i}$ were determined at $100 \mu \mathrm{M}$ by Griess assay over a duration of 0-60 min. As shown in Figure 2, variable levels of NO were produced by compounds $9 \mathbf{a}-\mathbf{i}$ and $13 \mathbf{a}-\mathbf{i}$. The concentration of NO increased with time, and at the time point of $60 \mathrm{~min}$, all tested compounds produced more than $15 \mu \mathrm{mol} / \mathrm{L}$ of NO. The amount of NO released by compounds $\mathbf{1 3 a}-\mathbf{i}$ (13g with the lowest level of $16.88 \mu \mathrm{mol} / \mathrm{L}$ at the $60 \mathrm{~min}$ time point) was less than that of $9 \mathbf{a}-\mathbf{i}$ (9d with the highest level of $45.44 \mu \mathrm{mol} / \mathrm{L}$ at the $60 \mathrm{~min}$ time point).

Figure 2. Variable levels of NO produced by compounds (a) $9 \mathbf{a}-\mathbf{i}$ and (b) 13a-i.
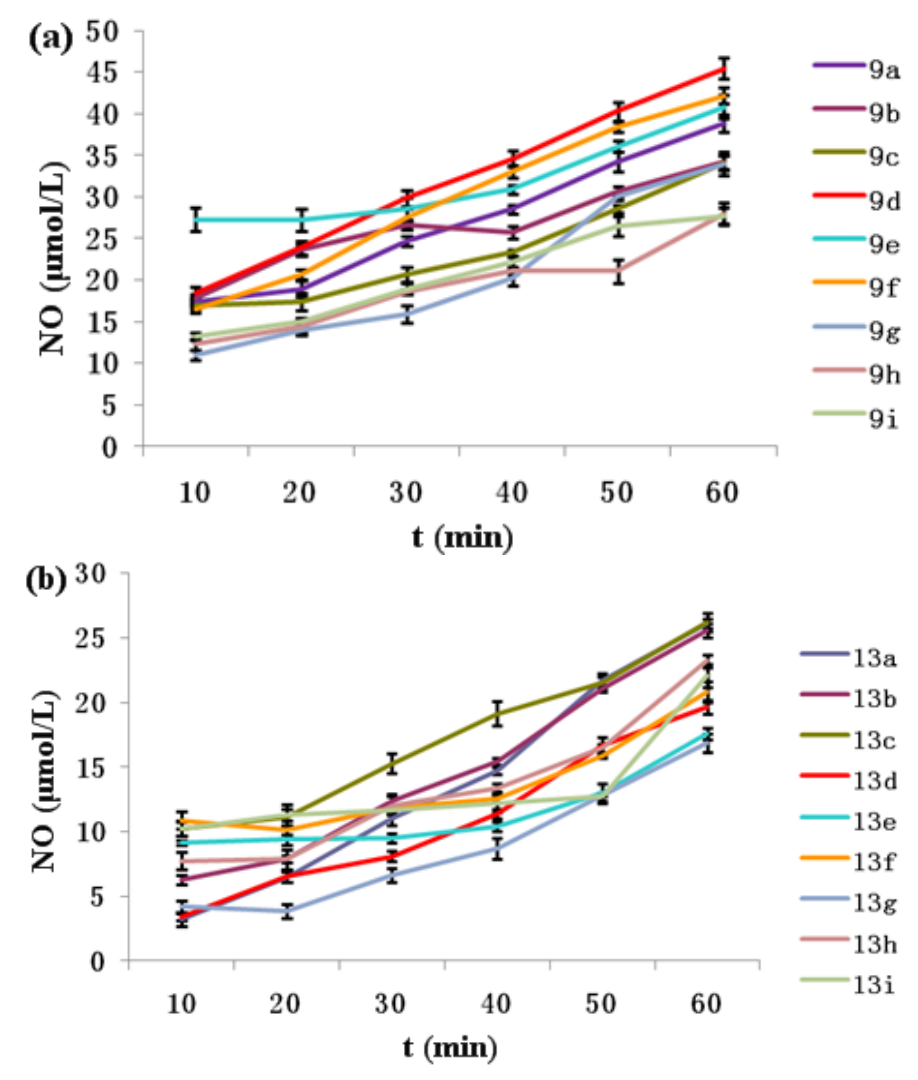


\subsection{Anti-proliferative Activity in Vitro}

The anti-proliferative activity of oridonin and its NO-donor hybrids 9a-i as well as 1-O-derivatives of oridonin (12) and its NO-donor hybrids 13a-i was evaluated against four human cancer cell lines (Bel-7402, K562, MGC-803, CaEs-17) by MTT assay. The results are shown in Table 1 [22]. All the target compounds $9 \mathbf{a}-\mathbf{i}$ and $\mathbf{1 3 a}-\mathbf{i}$ exhibited stronger anti-proliferative activity than their parent compounds 1 (oridonin) and 12 (1-oxo-oridonin), correspondingly. Among them, 13a-i released less NO (Figure 2) and showed less potent anti-proliferative activity than $\mathbf{9 a}-\mathbf{i}$. For example, $\mathbf{1 3 e}$ with $\mathrm{IC}_{50}$ value of $2.13 \mu \mathrm{M}$ compared to $9 \mathrm{e}(1.33 \mu \mathrm{M})$ against Bel-7402 cells, $\mathbf{1 3 g}$ with $\mathrm{IC}_{50}$ value of $2.45 \mu \mathrm{M}$ compared to $9 \mathrm{~g}(1.33 \mu \mathrm{M})$ against MGC803 cells, and so on. These results and our previous studies [13-17] indicated that the releasing of NO contributed to anti-proliferative activity and higher levels of NO releasing could produce stronger activity.

Table 1. $\mathrm{IC}_{50}$ values of the furoxan/oridonin hybrids against four human tumor cell lines ${ }^{a}$.

\begin{tabular}{ccccc}
\hline Compd. & Bel-7402 & K562 $^{c}$ & MGC-803 & CaEs-17 \\
\hline Taxol $^{b}$ & $1.89 \pm 0.09$ & $0.41 \pm 0.02^{c}$ & $0.85 \pm 0.06^{c}$ & $0.43 \pm 0.03^{d}$ \\
Oridonin & $7.48 \pm 0.53$ & $4.76 \pm 0.32$ & $5.69 \pm 0.39$ & $11.03 \pm 1.02$ \\
9a & $2.37 \pm 0.85$ & $4.33 \pm 0.14$ & $3.22 \pm 0.19$ & $8.46 \pm 0.05$ \\
9b & $1.91 \pm 0.09$ & $3.46 \pm 0.60$ & $2.57 \pm 0.07$ & $6.98 \pm 0.20$ \\
9c & $2.23 \pm 0.04$ & $4.02 \pm 0.05$ & $3.46 \pm 0.23$ & $8.17 \pm 1.01$ \\
9d & $1.89 \pm 0.22$ & $3.78 \pm 0.19$ & $3.08 \pm 0.47$ & $8.04 \pm 0.18$ \\
9e & $1.33 \pm 0.15$ & $2.85 \pm 0.03$ & $2.21 \pm 0.16$ & $6.77 \pm 0.32$ \\
9f & $1.97 \pm 0.04$ & $3.72 \pm 0.26$ & $3.23 \pm 0.25$ & $8.09 \pm 0.47$ \\
9g & $0.95 \pm 0.21^{c}$ & $1.94 \pm 0.14$ & $1.98 \pm 0.13$ & $4.81 \pm 0.10^{c}$ \\
9h & $0.86 \pm 0.08^{c}$ & $1.82 \pm 0.07$ & $1.81 \pm 0.20$ & $4.56 \pm 0.32^{c}$ \\
9i & $0.97 \pm 0.10^{c}$ & $1.92 \pm 0.34$ & $1.90 \pm 0.11$ & $5.24 \pm 0.18$ \\
$\mathbf{1 2}$ & $3.21 \pm 0.25$ & $5.06 \pm 0.18$ & $4.05 \pm 0.04$ & $7.24 \pm 0.41$ \\
$\mathbf{1 3 a}$ & $2.85 \pm 0.14$ & $4.65 \pm 0.07$ & $3.77 \pm 0.31$ & $5.30 \pm 0.28$ \\
$\mathbf{1 3 b}$ & $2.19 \pm 0.19$ & $3.85 \pm 0.06$ & $2.90 \pm 0.12$ & $4.11 \pm 0.07^{c}$ \\
$\mathbf{1 3 c}$ & $2.76 \pm 0.42$ & $4.11 \pm 0.15$ & $3.65 \pm 0.40$ & $5.22 \pm 0.12^{c}$ \\
$\mathbf{1 3 d}$ & $2.70 \pm 0.09$ & $4.08 \pm 0.30$ & $3.64 \pm 0.12$ & $5.38 \pm 0.24$ \\
$\mathbf{1 3 e}$ & $2.13 \pm 0.17$ & $3.04 \pm 0.21$ & $2.79 \pm 0.10$ & $4.00 \pm 0.31^{c}$ \\
$\mathbf{1 3 f}$ & $2.66 \pm 0.30$ & $3.97 \pm 0.16$ & $3.42 \pm 0.27$ & $5.11 \pm 0.39$ \\
$\mathbf{1 3 g}$ & $1.94 \pm 0.13$ & $2.22 \pm 0.29$ & $2.45 \pm 0.51$ & $3.28 \pm 0.06^{c}$ \\
$\mathbf{1 3 h}$ & $1.72 \pm 0.08$ & $2.08 \pm 0.34$ & $2.22 \pm 0.29$ & $3.24 \pm 0.23^{c}$ \\
$\mathbf{1 3 i}$ & $1.86 \pm 0.15$ & $2.65 \pm 0.08$ & $2.41 \pm 0.16$ & $3.13 \pm 0.21^{c}$ \\
\hline
\end{tabular}

${ }^{\mathrm{a}}$ Results are expressed as $\mathrm{IC}_{50}$ values in $\mu \mathrm{M}$ and the values are means $\pm \mathrm{SD} ; \mathrm{n}=3$. $^{\mathrm{b}}$ Taxol was used as a positive control. ${ }^{c} p<0.05$ versus oridonin; ${ }^{d} p<0.01$ versus oridonin.

Among the tested compounds, the series $\mathbf{9 g}-\mathbf{i}$ and $\mathbf{1 3 g}-\mathbf{i}$ with a $o-\mathrm{C}_{6} \mathrm{H}_{4}$ linker $\left(\mathrm{R}_{1}\right)$ (compounds $\left.\mathbf{g}-\mathbf{i}\right)$ showed lower $\mathrm{IC}_{50}$ values than the corresponding compounds $\mathbf{a}-\mathbf{f}$. Compared the $\mathrm{IC}_{50}$ values of the compounds of series $\mathbf{a}-\mathbf{c}$ with $\mathbf{d}-\mathbf{f}$ in different cell lines, there was a decline with the extension of the length of $\mathrm{R}_{1}$. In general, when $\mathrm{R}_{1}$ were aromatic groups (compounds $\mathbf{g}-\mathbf{i}$ ), the activity was stronger than those with alkyl groups. While $\mathrm{R}_{1}$ were alkyl groups, $\mathrm{IC}_{50}$ values decreased with lengthening of carbon chain. In almost all cases (except 13h), when the length of $R_{2}$ is three carbons, more potential 
anti-proliferative activity was observed than those of two and four carbons, correspondingly (for instance, 9b $>9 \mathrm{a}$ and $9 \mathrm{c}, 9 \mathrm{e}>9 \mathrm{~d}$ and $9 \mathrm{f}, 9 \mathrm{~h}>9 \mathrm{~g}$ and $9 \mathrm{i}, 13 \mathrm{~b}>13 \mathrm{a}$ and 13c, 13e $>13 \mathrm{~d}$ and 13f). This suggested that the length of the linker group $\mathrm{R}_{2}$ with three carbons would be more suitable. In all the target synthetic hybrids, compound $9 \mathbf{h}\left(\mathrm{R}_{1}=O-\mathrm{C}_{6} \mathrm{H}_{4} ; \mathrm{R}_{2}=\mathrm{CH}_{2} \mathrm{CH}_{2} \mathrm{CH}_{2}\right)$ exhibited the most potential anti-tumor activity against tested cell lines: $\mathrm{IC}_{50}$ values of $0.86 \mu \mathrm{M}$ against Bel-7402 (stronger than parent compound oridonin of $7.48 \mu \mathrm{M}$ and positive control taxol of $1.89 \mu \mathrm{M}$ ), $1.82 \mu \mathrm{M}$ against K562, $1.81 \mu \mathrm{M}$ against MGC-803 (stronger than oridonin of $5.69 \mu \mathrm{M}$ ) and $4.56 \mu \mathrm{M}$ against CaEs-17 (stronger than oridonin of $11.03 \mu \mathrm{M}$ ). Subsequent design and synthesis of novel NO releasing anti-tumor agents based on present SAR and more intensive biological studies were undertaking.

\section{Experimental}

\subsection{Chemistry}

All commercially available solvents and reagents were used without further purification. Melting points were taken on XT-4 micro melting point apparatus and are uncorrected. Infrared (IR) spectra (KBr pellets) were recorded on a Nicolet Impact 410 instrument (Madison, WI, USA). ${ }^{1} \mathrm{H}-\mathrm{NMR}$ spectra were recorded at $300 \mathrm{MHz}$ with a Bruker AV-300 spectrometer (Karlsruhe, Germany) in the indicated solvents (TMS as internal standard): The values of the chemical shifts are expressed in $\delta$ values (ppm) and the coupling constants $(J)$ in Hz. Mass spectra were obtained using FTMS-2000 (Madison, WI, USA). HR-MS were obtained using an Agilent QTOF 6520 (Palo Alto, CA, USA). Compounds 2-4 were commercially available. Compounds 5, 6, 7a-c, 10, 11 and 12 were synthesized, as previously described $[13,19,20]$.

\subsubsection{General Procedure for the Preparation of $\mathbf{8 a}-\mathbf{i}$}

Compound $7 \mathbf{a}-\mathbf{c}(2 \mathrm{mmol})$ in pyridine $(5 \mathrm{~mL})$ was mixed with the corresponding anhydride (4 mmol) by stirring at room temperature for 6-12 h. The mixture was concentrated in vacuo, dissolved in $\mathrm{H}_{2} \mathrm{O}(15 \mathrm{~mL})$ and extracted with $\mathrm{CH}_{2} \mathrm{Cl}_{2}(15 \mathrm{~mL} \times 3)$. The organic layers were combined, washed with water and saturated $\mathrm{NaCl}$ solution sequentially, dried over anhydrous $\mathrm{Na}_{2} \mathrm{SO}_{4}$, and concentrated in vacuo. The crude products 8a-i used for the next step without further purification.

\subsubsection{General Procedure for the Preparation of $\mathbf{9 a}-\mathbf{i}$ and $\mathbf{1 3 a}-\mathbf{i}$}

Compounds 8a-i $(0.24 \mathrm{mmol})$ were dissolved in $\mathrm{CH}_{2} \mathrm{Cl}_{2}(10 \mathrm{~mL})$ and stirred at room temperature. Oridonin or its derivative $12(0.2 \mathrm{mmol})$, EDCI (93 mg, $0.6 \mathrm{mmol})$ and DMAP (catalytic amount) were added. After 8-12 $\mathrm{h}$, the reaction mixture was washed with water and saturated $\mathrm{NaCl}$ solution sequentially, dried over anhydrous $\mathrm{Na}_{2} \mathrm{SO}_{4}$, and concentrated in vacuo. The crude products were purified by column chromatography $\left(\mathrm{MeOH} / \mathrm{CH}_{2} \mathrm{Cl}_{2}\right.$ 1:200 v/v) to give the title compounds.

ent-1 $\alpha, 6 \beta, 7 \beta$-Trihydroxy-(14 $\beta$-O-(4-oxo-butyric acid-(3-phenylsulfonyl-1,2,5-oxadiazole-2-oxide-4) oxyethyl))-15-oxo-7,20-epoxy-16-kaurene (9a). Yield 41\%, m.p. 93-95 ${ }^{\circ} \mathrm{C} ;{ }^{1} \mathrm{H}-\mathrm{NMR}\left(\mathrm{CDCl}_{3}\right), \delta$ (ppm) $1.12\left(3 \mathrm{H}, \mathrm{s},-\mathrm{CH}_{3}\right), 1.25\left(3 \mathrm{H}, \mathrm{s},-\mathrm{CH}_{3}\right), 3.16(1 \mathrm{H}, \mathrm{d}, J=9.6 \mathrm{~Hz}, 13-\mathrm{CH}), 3.49(1 \mathrm{H}, \mathrm{m}, 1-\mathrm{CH}), 3.76$ $(1 \mathrm{H}, \mathrm{m}, 6-\mathrm{CH}), 4.02(1 \mathrm{H}, \mathrm{s}, 1-\mathrm{OH}), 4.06,4.30\left(\right.$ each $\left.1 \mathrm{H}, \mathrm{dd}, J_{\mathrm{A}}=J_{\mathrm{B}}=10.2 \mathrm{~Hz}, 20-\mathrm{CH}_{2}\right), 4.51(2 \mathrm{H}, \mathrm{t}$, 
$\left.J=4.5 \mathrm{~Hz},-\mathrm{CH}_{2}\right), 4.62\left(2 \mathrm{H}, \mathrm{t}, J=4.8 \mathrm{~Hz},-\mathrm{CH}_{2}\right), 5.53\left(1 \mathrm{H}, \mathrm{s}, 17-\mathrm{CH}_{2}\right), 5.92(1 \mathrm{H}, \mathrm{s}, 14-\mathrm{CH}), 6.04$ $(1 \mathrm{H}, \mathrm{d}, J=10.8 \mathrm{~Hz}, 6-\mathrm{OH}), 6.15\left(1 \mathrm{H}, \mathrm{s}, 17-\mathrm{CH}_{2}\right), 7.64(2 \mathrm{H}, \mathrm{t}, J=7.2 \mathrm{~Hz}, \mathrm{Ar}-\mathrm{H}), 7.77(1 \mathrm{H}, \mathrm{t}, J=7.5 \mathrm{~Hz}$, Ar-H), 8.07 (2H, d, $J=8.1 \mathrm{~Hz}, \mathrm{Ar}-\mathrm{H})$; MS(ESI) $m / z$ : $755.4[\mathrm{M}+\mathrm{Na}]^{+}$; HR-MS (ESI, M+Na) $m / z$ : calcd for $\mathrm{C}_{34} \mathrm{H}_{40} \mathrm{~N}_{2} \mathrm{NaO}_{14} \mathrm{~S}: 755.2092$, found 755.2095.

ent-1 $\alpha, 6 \beta, 7 \beta$-Trihydroxy-(14 $\beta$-O-(4-oxobutyric acid-(3-phenylsulfonyl-1,2,5-oxadiazole-2-oxide-4)oxypropyl))-15-oxo-7,20-epoxy-16-kaurene (9b). Yield 34\%, m.p. 86-88 ${ }^{\circ} \mathrm{C}$; IR $v_{\max } 3419$, 2955, 2025, 1736, 1615, 1554, 1451, 1359, 733, $686 \mathrm{~cm}^{-1} ;{ }^{1} \mathrm{H}-\mathrm{NMR}\left(\mathrm{CDCl}_{3}\right), \delta(\mathrm{ppm}) 1.11\left(6 \mathrm{H}, \mathrm{s},-\mathrm{CH}_{3}\right)$, $3.14(1 \mathrm{H}, \mathrm{d}, J=9.6 \mathrm{~Hz}, 13-\mathrm{CH}), 3.49(1 \mathrm{H}, \mathrm{m}, 1-\mathrm{CH}), 3.74(1 \mathrm{H}, \mathrm{m}, 6-\mathrm{CH}), 4.07(1 \mathrm{H}, \mathrm{s}, 1-\mathrm{OH}), 4.28$ $\left(2 \mathrm{H}, \mathrm{m},-\mathrm{CH}_{2}\right), 4.06,4.30\left(\right.$ each $\left.1 \mathrm{H}, \mathrm{dd}, J_{\mathrm{A}}=J_{\mathrm{B}}=10.2 \mathrm{~Hz}, 20-\mathrm{CH}_{2}\right), 4.50\left(2 \mathrm{H}, \mathrm{t}, J=6.0 \mathrm{~Hz},-\mathrm{CH}_{2}\right)$, $5.52\left(1 \mathrm{H}, \mathrm{s}, 17-\mathrm{CH}_{2}\right), 5.89(1 \mathrm{H}, \mathrm{s}, 14-\mathrm{CH}), 6.07(1 \mathrm{H}, \mathrm{d}, J=10.8 \mathrm{~Hz}, 6-\mathrm{OH}), 6.15\left(1 \mathrm{H}, \mathrm{s}, 17-\mathrm{CH}_{2}\right), 7.63$ $(2 \mathrm{H}, \mathrm{t}, J=7.8 \mathrm{~Hz}, \mathrm{Ar}-\mathrm{H}), 7.77(1 \mathrm{H}, \mathrm{t}, J=7.2 \mathrm{~Hz}, \mathrm{Ar}-\mathrm{H}), 8.06(2 \mathrm{H}, \mathrm{d}, J=7.2 \mathrm{~Hz}, \mathrm{Ar}-\mathrm{H})$; MS(ESI) $m / z$ : $764.3\left[\mathrm{M}+\mathrm{NH}_{4}\right]^{+}, \quad 747.3[\mathrm{M}+\mathrm{H}]^{+}, \quad 781.4 \quad[\mathrm{M}+\mathrm{Cl}]^{-}$; HR-MS (ESI, M+Na) $\mathrm{m} / \mathrm{z}$ : calcd for $\mathrm{C}_{35} \mathrm{H}_{42} \mathrm{~N}_{2} \mathrm{NaO}_{14} \mathrm{~S}: 769.2249$, found 769.2254.

ent-1 $\alpha, 6 \beta, 7 \beta$-Trihydroxy-(14 $\beta$-O-(4-oxobutyric acid-(3-phenylsulfonyl-1,2,5-oxadiazole-2-oxide-4)oxybutyl))-15-oxo-7,20-epoxy-16-kaurene (9c). Yield 48\%, m.p. 83-85 ${ }^{\circ} \mathrm{C}$; IR $v_{\max } 3417,2955,2025$, 1734, 1635, 1554, 1451, 1367, 733, $686 \mathrm{~cm}^{-1} ;{ }^{1} \mathrm{H}-\mathrm{NMR}\left(\mathrm{CDCl}_{3}\right), \delta(\mathrm{ppm}) 1.11\left(6 \mathrm{H}, \mathrm{s},-\mathrm{CH}_{3}\right), 3.15$ $(1 \mathrm{H}, \mathrm{d}, J=9.6 \mathrm{~Hz}, 13-\mathrm{CH}), 3.48(1 \mathrm{H}, \mathrm{m}, 1-\mathrm{CH}), 3.75(1 \mathrm{H}, \mathrm{m}, 6-\mathrm{CH}), 4.07(1 \mathrm{H}, \mathrm{s}, 1-\mathrm{OH}), 4.17(2 \mathrm{H}, \mathrm{m}$, $\left.-\mathrm{CH}_{2}\right), 4.05,4.29\left(\right.$ each $\left.1 \mathrm{H}, \mathrm{dd}, J_{\mathrm{A}}=J_{\mathrm{B}}=11.1 \mathrm{~Hz}, 20-\mathrm{CH}_{2}\right), 4.45\left(2 \mathrm{H}, \mathrm{t}, J=6.0 \mathrm{~Hz},-\mathrm{CH}_{2}\right), 5.52(1 \mathrm{H}$, s, 17- $\left.\mathrm{CH}_{2}\right), 5.90(1 \mathrm{H}, \mathrm{s}, 14-\mathrm{CH}), 6.06(1 \mathrm{H}, \mathrm{d}, J=10.8 \mathrm{~Hz}, 6-\mathrm{OH}), 6.15\left(1 \mathrm{H}, \mathrm{s}, 17-\mathrm{CH}_{2}\right), 7.63(2 \mathrm{H}, \mathrm{t}$, $J=7.5 \mathrm{~Hz}, \mathrm{Ar}-\mathrm{H}), 7.77(1 \mathrm{H}, \mathrm{t}, J=7.2 \mathrm{~Hz}, \mathrm{Ar}-\mathrm{H}), 8.06(2 \mathrm{H}, \mathrm{d}, J=7.2 \mathrm{~Hz}, \mathrm{Ar}-\mathrm{H})$; MS(ESI) $m / z: 778.2$ $\left[\mathrm{M}+\mathrm{NH}_{4}\right]^{+}, 761.1[\mathrm{M}+\mathrm{H}]^{+}, 795.2[\mathrm{M}+\mathrm{Cl}]^{-}$; HR-MS (ESI, M+Na) $m / z$ : calcd for $\mathrm{C}_{36} \mathrm{H}_{44} \mathrm{~N}_{2} \mathrm{NaO}_{14} \mathrm{~S}$ : 783.2405, found 783.2411 .

ent-1 $\alpha, 6 \beta, 7 \beta$-Trihydroxy-(14/-O-(5-oxo-pentanoic acid-(3-phenylsulfonyl-1,2,5-oxadiazole-2-oxide4)-oxyethyl))-15-oxo-7,20-epoxy-16-kaurene (9d). Yield 45\%, m.p. 86-89 ${ }^{\circ} \mathrm{C}$; IR $v_{\max } 3405,2952$, 2025, 1739, 1618, 1554, 1451, 1360, 732, $676 \mathrm{~cm}^{-1} ;{ }^{1} \mathrm{H}-\mathrm{NMR}\left(\mathrm{CDCl}_{3}\right), \delta(\mathrm{ppm}) 1.10\left(6 \mathrm{H}, \mathrm{s},-\mathrm{CH}_{3}\right)$, $3.16(1 \mathrm{H}, \mathrm{d}, J=9.9 \mathrm{~Hz}, 13-\mathrm{CH}), 3.48(1 \mathrm{H}, \mathrm{m}, 1-\mathrm{CH}), 3.73(1 \mathrm{H}, \mathrm{m}, 6-\mathrm{CH}), 4.14(1 \mathrm{H}, \mathrm{s}, 1-\mathrm{OH}), 4.05$, $4.30\left(\right.$ each $\left.1 \mathrm{H}, \mathrm{dd}, J_{\mathrm{A}}=J_{\mathrm{B}}=10.2 \mathrm{~Hz}, 20-\mathrm{CH}_{2}\right), 4.47\left(2 \mathrm{H}, \mathrm{m},-\mathrm{CH}_{2}\right), 4.61\left(2 \mathrm{H}, \mathrm{m},-\mathrm{CH}_{2}\right), 5.50(1 \mathrm{H}, \mathrm{s}$, 17- $\left.\mathrm{CH}_{2}\right), 5.87(1 \mathrm{H}, \mathrm{s}, 14-\mathrm{CH}), 6.06(1 \mathrm{H}, \mathrm{d}, J=10.5 \mathrm{~Hz}, 6-\mathrm{OH}), 6.13\left(1 \mathrm{H}, \mathrm{s}, 17-\mathrm{CH}_{2}\right), 7.63(2 \mathrm{H}, \mathrm{t}$, $J=7.5 \mathrm{~Hz}, \mathrm{Ar}-\mathrm{H}), 7.77(1 \mathrm{H}, \mathrm{t}, J=7.5 \mathrm{~Hz}, \mathrm{Ar}-\mathrm{H}), 8.06(2 \mathrm{H}, \mathrm{d}, J=7.8 \mathrm{~Hz}, \mathrm{Ar}-\mathrm{H})$; MS(ESI) $m / z: 764.0$ $\left[\mathrm{M}+\mathrm{NH}_{4}\right]^{+}, 747.1[\mathrm{M}+\mathrm{H}]^{+}, 781.2[\mathrm{M}+\mathrm{Cl}]^{-}$; HR-MS (ESI, M+Na) $m / z$ : calcd for $\mathrm{C}_{35} \mathrm{H}_{42} \mathrm{~N}_{2} \mathrm{NaO}_{14} \mathrm{~S}$ : 769.2249, found 769.225 .

ent-1 $\alpha, 6 \beta, 7 \beta$-Trihydroxy-(14ק-O-(5-oxopentanoic acid-(3-phenylsulfonyl-1,2,5-oxadiazole-2-oxide-4)oxypropyl))-15-oxo-7,20-epoxy-16-kaurene (9e). Yield 42\%, m.p. 80-82 ${ }^{\circ} \mathrm{C}$; IR $v_{\max } 3439,2954,2025$, 1734, 1615, 1554, 1452, 1383, 733, $686 \mathrm{~cm}^{-1} ;{ }^{1} \mathrm{H}-\mathrm{NMR}\left(\mathrm{CDCl}_{3}\right), \delta(\mathrm{ppm}) 1.11\left(6 \mathrm{H}, \mathrm{s},-\mathrm{CH}_{3}\right), 3.16$ $(1 \mathrm{H}, \mathrm{d}, J=9.6 \mathrm{~Hz}, 13-\mathrm{CH}), 3.50(1 \mathrm{H}, \mathrm{m}, 1-\mathrm{CH}), 3.75(1 \mathrm{H}, \mathrm{m}, 6-\mathrm{CH}), 4.07,4.30$ (each 1H, dd, $\left.J_{\mathrm{A}}=J_{\mathrm{B}}=10.8 \mathrm{~Hz}, 20-\mathrm{CH}_{2}\right), 4.25\left(2 \mathrm{H}, \mathrm{t}, J=6.0 \mathrm{~Hz},-\mathrm{CH}_{2}\right), 4.50\left(2 \mathrm{H}, \mathrm{t}, J=6.0 \mathrm{~Hz},-\mathrm{CH}_{2}\right), 5.51(1 \mathrm{H}, \mathrm{s}$, 17- $\left.\mathrm{CH}_{2}\right), 5.87(1 \mathrm{H}, \mathrm{s}, 14-\mathrm{CH}), 6.05(1 \mathrm{H}, \mathrm{d}, J=10.5 \mathrm{~Hz}, 6-\mathrm{OH}), 6.14\left(1 \mathrm{H}, \mathrm{s}, 17-\mathrm{CH}_{2}\right), 7.63(2 \mathrm{H}, \mathrm{t}$, $J=7.5 \mathrm{~Hz}, \mathrm{Ar}-\mathrm{H}), 7.77(1 \mathrm{H}, \mathrm{t}, J=7.5 \mathrm{~Hz}, \mathrm{Ar}-\mathrm{H}), 8.05(2 \mathrm{H}, \mathrm{d}, J=7.5 \mathrm{~Hz}, \mathrm{Ar}-\mathrm{H})$; MS(ESI) $m / z: 778.3$ 
$\left[\mathrm{M}+\mathrm{NH}_{4}\right]^{+}, 761.3[\mathrm{M}+\mathrm{H}]^{+}, 795.4[\mathrm{M}+\mathrm{Cl}]^{-}$; HR-MS (ESI, M+Na) $m / z$ : calcd for $\mathrm{C}_{36} \mathrm{H}_{44} \mathrm{~N}_{2} \mathrm{NaO}_{14} \mathrm{~S}$ : 783.2405, found 783.2419.

ent-1 $\alpha, 6 \beta, 7 \beta$-Trihydroxy-(14 $\beta$-O-(5-oxo-pentanoic acid-(3-phenylsulfonyl-1,2,5-oxadiazole-2-oxide4)-oxybutyl))-15-oxo-7,20-epoxy-16-kaurene (9f). Yield 37\%, m.p. 92-94 ${ }^{\circ} \mathrm{C}$; IR $v_{\max } 3440,2955$, 2025, 1733, 1615, 1554, 1451, 1367, 732, $686 \mathrm{~cm}^{-1} ;{ }^{1} \mathrm{H}-\mathrm{NMR}\left(\mathrm{CDCl}_{3}\right), \delta(\mathrm{ppm}) 1.11\left(6 \mathrm{H}, \mathrm{s},-\mathrm{CH}_{3}\right)$, $3.39(1 \mathrm{H}, \mathrm{d}, J=9.9 \mathrm{~Hz}, 13-\mathrm{CH}), 3.50(1 \mathrm{H}, \mathrm{m}, 1-\mathrm{CH}), 3.76(1 \mathrm{H}, \mathrm{m}, 6-\mathrm{CH}), 4.06(1 \mathrm{H}, \mathrm{s}, 1-\mathrm{OH}), 4.08$, $4.34\left(\right.$ each $\left.1 \mathrm{H}, \mathrm{dd}, J_{\mathrm{A}}=J_{\mathrm{B}}=10.2 \mathrm{~Hz}, 20-\mathrm{CH}_{2}\right), 4.46\left(1 \mathrm{H}, \mathrm{m},-\mathrm{CH}_{2}\right), 4.57\left(1 \mathrm{H}, \mathrm{m},-\mathrm{CH}_{2}\right), 4.58(2 \mathrm{H}, \mathrm{m}$, $\left.-\mathrm{CH}_{2}\right), 5.56\left(1 \mathrm{H}, \mathrm{s}, 17-\mathrm{CH}_{2}\right), 6.05(1 \mathrm{H}, \mathrm{d}, J=10.5 \mathrm{~Hz}, 6-\mathrm{OH}), 6.07(1 \mathrm{H}, \mathrm{s}, 14-\mathrm{CH}), 6.17(1 \mathrm{H}, \mathrm{s}$, 17- $\left.\mathrm{CH}_{2}\right), 7.52$ (2H, m, Ar-H), $7.57(3 \mathrm{H}, \mathrm{m}, \mathrm{Ar}-\mathrm{H}), 7.75(2 \mathrm{H}, \mathrm{m}, \mathrm{Ar}-\mathrm{H}), 8.06(2 \mathrm{H}, \mathrm{d}, J=7.5 \mathrm{~Hz}, \mathrm{Ar}-\mathrm{H})$; MS(ESI) $m / z: 792.3\left[\mathrm{M}+\mathrm{NH}_{4}\right]^{+}, 775.5[\mathrm{M}+\mathrm{H}]^{+}, 809.6[\mathrm{M}+\mathrm{Cl}]^{-}$; HR-MS (ESI, M+Na) $\mathrm{m} / z$ : calcd for $\mathrm{C}_{37} \mathrm{H}_{46} \mathrm{~N}_{2} \mathrm{NaO}_{14} \mathrm{~S}: 797.2562$, found 797.2565.

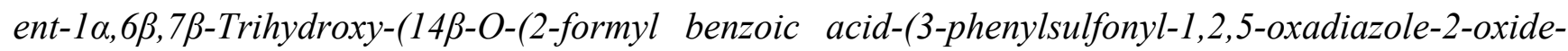
4)-oxyethyl))-15-oxo-7,20-epoxy-16-kaurene (9g). Yield 53\%, m.p. 123-125 ${ }^{\circ} \mathrm{C}$; IR $v_{\max } 3392,2951$, 2025, 1714, 1618, 1553, 1451, 1363, 739, $685 \mathrm{~cm}^{-1} ;{ }^{1} \mathrm{H}-\mathrm{NMR}\left(\mathrm{CDCl}_{3}\right), \delta(\mathrm{ppm}) 1.09\left(6 \mathrm{H}, \mathrm{s},-\mathrm{CH}_{3}\right)$, $3.37(1 \mathrm{H}, \mathrm{d}, J=9.6 \mathrm{~Hz}, 13-\mathrm{CH}), 3.50(1 \mathrm{H}, \mathrm{m}, 1-\mathrm{CH}), 3.72(1 \mathrm{H}, \mathrm{m}, 6-\mathrm{CH}), 4.05(1 \mathrm{H}, \mathrm{s}, 1-\mathrm{OH}), 4.07$, $4.36\left(\right.$ each $\left.1 \mathrm{H}, \mathrm{dd}, J_{\mathrm{A}}=J_{\mathrm{B}}=10.2 \mathrm{HZ}, 20-\mathrm{CH}_{2}\right), 4.67\left(2 \mathrm{H}, \mathrm{m},-\mathrm{CH}_{2}\right), 4.76\left(2 \mathrm{H}, \mathrm{m},-\mathrm{CH}_{2}\right), 5.54(1 \mathrm{H}, \mathrm{s}$, 17- $\left.\mathrm{CH}_{2}\right), 6.04(1 \mathrm{H}, \mathrm{d}, J=12.0 \mathrm{~Hz}, 6-\mathrm{OH}), 6.07(1 \mathrm{H}, \mathrm{s}, 14-\mathrm{CH}), 6.14\left(1 \mathrm{H}, \mathrm{s}, 17-\mathrm{CH}_{2}\right), 7.46(2 \mathrm{H}, \mathrm{t}$, $J=7.8 \mathrm{~Hz}, \mathrm{Ar}-\mathrm{H}), 7.58(4 \mathrm{H}, \mathrm{m}, \mathrm{Ar}-\mathrm{H}), 7.78(1 \mathrm{H}, \mathrm{m}, \mathrm{Ar}-\mathrm{H}), 8.01$ (2H, d, $J=7.5 \mathrm{~Hz}, \mathrm{Ar}-\mathrm{H})$; MS(ESI) $m / z: 798.3\left[\mathrm{M}+\mathrm{NH}_{4}\right]^{+}, 781.2[\mathrm{M}+\mathrm{H}]^{+}, 815.3[\mathrm{M}+\mathrm{Cl}]^{-}$; HR-MS (ESI, M+Na) $\mathrm{m} / z$ : calcd for $\mathrm{C}_{38} \mathrm{H}_{40} \mathrm{~N}_{2} \mathrm{NaO}_{14} \mathrm{~S}: 803.2092$, found 755.2093.

ent-1 $\alpha, 6 \beta, 7 \beta$-Trihydroxy-(14 $\beta$-O-(2-formyl benzoic acid-(3-phenylsulfonyl-1,2,5-oxadiazole-2-oxide4)-oxypropyl))-15-oxo-7,20-epoxy-16-kaurene (9h). Yield 47\%, m.p. 113-115 ${ }^{\circ} \mathrm{C}$; IR $v_{\max } 3418,2954$, 2025, 1714, 1616, 1554, 1451, 1384, 736, $685 \mathrm{~cm}^{-1} ;{ }^{1} \mathrm{H}-\mathrm{NMR}\left(\mathrm{CDCl}_{3}\right), \delta(\mathrm{ppm}) 1.11\left(6 \mathrm{H}, \mathrm{s},-\mathrm{CH}_{3}\right)$, $3.39(1 \mathrm{H}, \mathrm{d}, J=9.9 \mathrm{~Hz}, 13-\mathrm{CH}), 3.50(1 \mathrm{H}, \mathrm{m}, 1-\mathrm{CH}), 3.76(1 \mathrm{H}, \mathrm{m}, 6-\mathrm{CH}), 4.06(1 \mathrm{H}, \mathrm{s}, 1-\mathrm{OH}), 4.08$, $4.34\left(\right.$ each $\left.1 \mathrm{H}, \mathrm{dd}, J_{\mathrm{A}}=J_{\mathrm{B}}=10.2 \mathrm{~Hz}, 20-\mathrm{CH}_{2}\right), 4.46\left(1 \mathrm{H}, \mathrm{m},-\mathrm{CH}_{2}\right), 4.57\left(1 \mathrm{H}, \mathrm{m},-\mathrm{CH}_{2}\right), 4.58(2 \mathrm{H}, \mathrm{m}$, $\left.-\mathrm{CH}_{2}\right), 5.56\left(1 \mathrm{H}, \mathrm{s}, 17-\mathrm{CH}_{2}\right), 6.05(1 \mathrm{H}, \mathrm{d}, J=10.5 \mathrm{~Hz}, 6-\mathrm{OH}), 6.07(1 \mathrm{H}, \mathrm{s}, 14-\mathrm{CH}), 6.17(1 \mathrm{H}, \mathrm{s}$, 17- $\left.\mathrm{CH}_{2}\right), 7.52(2 \mathrm{H}, \mathrm{m}, \mathrm{Ar}-\mathrm{H}), 7.57(3 \mathrm{H}, \mathrm{m}, \mathrm{Ar}-\mathrm{H}), 7.75(2 \mathrm{H}, \mathrm{m}, \mathrm{Ar}-\mathrm{H}), 8.06(2 \mathrm{H}, \mathrm{d}, J=7.5 \mathrm{~Hz}, \mathrm{Ar}-\mathrm{H})$; MS(ESI) $m / z: 812.3\left[\mathrm{M}+\mathrm{NH}_{4}\right]^{+}, 795.3[\mathrm{M}+\mathrm{H}]^{+}, 829.4[\mathrm{M}+\mathrm{Cl}]^{-}$; HR-MS (ESI, M+Na) $\mathrm{m} / z$ : calcd for $\mathrm{C}_{39} \mathrm{H}_{42} \mathrm{~N}_{2} \mathrm{NaO}_{14} \mathrm{~S}: 817.2249$, found 755.2252.

ent-1 $\alpha, 6 \beta, 7 \beta$-Trihydroxy-(14ק-O-(2-formylbenzoic acid-(3-phenylsulfonyl-1,2,5-oxadiazole-2-oxide4)-oxybutyl))-15-oxo-7,20-epoxy-16-kaurene (9i). Yield 50\%, m.p. $108-110{ }^{\circ} \mathrm{C}$; IR $v_{\max } 3384,2952$, 2025, 1715, 1615, 1553, 1450, 1368, 734, $685 \mathrm{~cm}^{-1} ;{ }^{1} \mathrm{H}-\mathrm{NMR}\left(\mathrm{CDCl}_{3}\right), \delta(\mathrm{ppm}) 1.10\left(6 \mathrm{H}, \mathrm{s},-\mathrm{CH}_{3}\right)$, $3.32(1 \mathrm{H}, \mathrm{d}, J=9.9 \mathrm{~Hz}, 13-\mathrm{CH}), 3.50(1 \mathrm{H}, \mathrm{m}, 1-\mathrm{CH}), 3.76(1 \mathrm{H}, \mathrm{m}, 6-\mathrm{CH}), 4.08,4.34$ (each 1H, dd, $\left.J_{\mathrm{A}}=J_{\mathrm{B}}=8.4 \mathrm{HZ}, 20-\mathrm{CH}_{2}\right), 4.44\left(2 \mathrm{H}, \mathrm{m},-\mathrm{CH}_{2}\right), 4.50\left(2 \mathrm{H}, \mathrm{t}, J=5.4 \mathrm{~Hz},-\mathrm{CH}_{2}\right), 5.30(1 \mathrm{H}, \mathrm{s}, 1-\mathrm{OH})$, $5.56\left(1 \mathrm{H}, \mathrm{s}, 17-\mathrm{CH}_{2}\right), 6.04(1 \mathrm{H}, \mathrm{d}, J=10.5 \mathrm{~Hz}, 6-\mathrm{OH}), 6.09(1 \mathrm{H}, \mathrm{s}, 14-\mathrm{CH}), 6.61\left(1 \mathrm{H}, \mathrm{s}, 17-\mathrm{CH}_{2}\right), 7.53$ $(3 \mathrm{H}, \mathrm{m}, \mathrm{Ar}-\mathrm{H}), 7.61(2 \mathrm{H}, \mathrm{m}, \mathrm{Ar}-\mathrm{H}), 7.76(2 \mathrm{H}, \mathrm{m}, \mathrm{Ar}-\mathrm{H}), 8.06(2 \mathrm{H}, \mathrm{d}, J=7.8 \mathrm{~Hz}, \mathrm{Ar}-\mathrm{H})$; MS(ESI) $m / z$ : $826.1\left[\mathrm{M}+\mathrm{NH}_{4}\right]^{+}, 809.0[\mathrm{M}+\mathrm{H}]^{+}, 843.3[\mathrm{M}+\mathrm{Cl}]^{-}$; HR-MS (ESI, M+Na) $m / z$ : calcd for $\mathrm{C}_{40} \mathrm{H}_{44} \mathrm{~N}_{2} \mathrm{NaO}_{14} \mathrm{~S}$ : 831.2405, found 831.2411. 


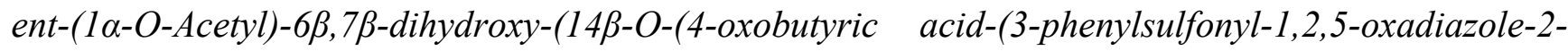
oxide-4)-oxyethyl))-15-oxo-7,20-epoxy-16-kaurene (13a). Yield 40\%, m.p. 105-107 ${ }^{\circ} \mathrm{C}$; IR $v_{\max } 3384$, 2958, 2025, 1739, 1618, 1554, 1452, 1363, 732, $686 \mathrm{~cm}^{-1} ;{ }^{1} \mathrm{H}-\mathrm{NMR}\left(\mathrm{CDCl}_{3}\right), \delta$ (ppm) $1.12(6 \mathrm{H}, \mathrm{s}$, $\left.-\mathrm{CH}_{3}\right), 2.17\left(3 \mathrm{H}, \mathrm{s},-\mathrm{CH}_{3}\right), 3.13(1 \mathrm{H}, \mathrm{d}, J=9.6 \mathrm{~Hz}, 13-\mathrm{CH}), 3.76(1 \mathrm{H}, \mathrm{m}, 6-\mathrm{CH}), 4.17,4.28$ (each 1H, $\left.\mathrm{dd}, J_{\mathrm{A}}=J_{\mathrm{B}}=10,5 \mathrm{~Hz}, 20-\mathrm{CH}_{2}\right), 4.51\left(2 \mathrm{H}, \mathrm{m},-\mathrm{CH}_{2}\right), 4.61(1 \mathrm{H}, \mathrm{m}, 1-\mathrm{CH}), 4.62\left(2 \mathrm{H}, \mathrm{m},-\mathrm{CH}_{2}\right), 5.52$ $\left(1 \mathrm{H}, \mathrm{s}, 17-\mathrm{CH}_{2}\right), 5.87(1 \mathrm{H}, \mathrm{s}, 14-\mathrm{CH}), 6.09(1 \mathrm{H}, \mathrm{d}, J=9.3 \mathrm{~Hz}, 6-\mathrm{OH}), 6.15\left(1 \mathrm{H}, \mathrm{s}, 17-\mathrm{CH}_{2}\right), 7.63(2 \mathrm{H}$, t, $J=7.2 \mathrm{~Hz}$, Ar-H), $7.91(1 \mathrm{H}, \mathrm{t}, J=7.8 \mathrm{~Hz}, \mathrm{Ar}-\mathrm{H}), 8.07(2 \mathrm{H}, \mathrm{d}, J=7.2 \mathrm{~Hz}, \mathrm{Ar}-\mathrm{H}) ; \mathrm{MS}(\mathrm{ESI}) m / z$ : $775.3[\mathrm{M}+\mathrm{H}]^{+}, 809.4[\mathrm{M}+\mathrm{Cl}]^{-}$; HR-MS (ESI, M+Na) $m / z$ : calcd for $\mathrm{C}_{36} \mathrm{H}_{42} \mathrm{~N}_{2} \mathrm{NaO}_{15} \mathrm{~S}$ : 797.2198 , found 797.2207 .

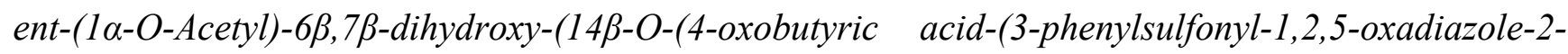
oxide-4)-oxypropyl))-15-oxo-7,20-epoxy-16-kaurene (13b). Yield 51\%, m.p. 95-97 ${ }^{\circ} \mathrm{C}$; IR $v_{\max } 3383$, 2957, 2025, 1738, 1615, 1554, 1452, 1373, 733, $686 \mathrm{~cm}^{-1} ;{ }^{1} \mathrm{H}-\mathrm{NMR}\left(\mathrm{CDCl}_{3}\right), \delta$ (ppm) $1.12(6 \mathrm{H}, \mathrm{s}$, $\left.-\mathrm{CH}_{3}\right), 1.99\left(3 \mathrm{H}, \mathrm{s},-\mathrm{CH}_{3}\right), 3.12(1 \mathrm{H}, \mathrm{d}, J=9.6 \mathrm{~Hz}, 13-\mathrm{CH}), 3.77(1 \mathrm{H}, \mathrm{m}, 6-\mathrm{CH}), 4.31\left(2 \mathrm{H}, \mathrm{m},-\mathrm{CH}_{2}\right)$, $4.17,4.34\left(\right.$ each $\left.1 \mathrm{H}, \mathrm{dd}, J_{\mathrm{A}}=J_{\mathrm{B}}=10.2 \mathrm{~Hz}, 20-\mathrm{CH}_{2}\right), 4.51\left(2 \mathrm{H}, \mathrm{t}, J=6.0 \mathrm{~Hz},-\mathrm{CH}_{2}\right), 4.62(1 \mathrm{H}, \mathrm{m}$, 1-CH), $5.52\left(1 \mathrm{H}, \mathrm{s}, 17-\mathrm{CH}_{2}\right), 5.85(1 \mathrm{H}, \mathrm{s}, 14-\mathrm{CH}), 6.12(1 \mathrm{H}, \mathrm{d}, J=11.1 \mathrm{~Hz}, 6-\mathrm{OH}), 6.15(1 \mathrm{H}, \mathrm{s}$, 17- $\left.\mathrm{CH}_{2}\right), 7.64(2 \mathrm{H}, \mathrm{t}, J=7.8 \mathrm{~Hz}, \operatorname{Ar}-\mathrm{H}), 7.77(1 \mathrm{H}, \mathrm{t}, J=7.5 \mathrm{~Hz}, \mathrm{Ar}-\mathrm{H}), 8.06(2 \mathrm{H}, \mathrm{d}, J=7.2 \mathrm{~Hz}$, Ar-H); MS(ESI) $m / z: 806.3\left[\mathrm{M}+\mathrm{NH}_{4}\right]^{+}, 789.3[\mathrm{M}+\mathrm{H}]^{+}, 823.3[\mathrm{M}+\mathrm{Cl}]^{-}$; HR-MS (ESI, M+Na) $m / z$ : calcd for $\mathrm{C}_{37} \mathrm{H}_{44} \mathrm{~N}_{2} \mathrm{NaO}_{15} \mathrm{~S}$ : 811.2355, found 811.2362.

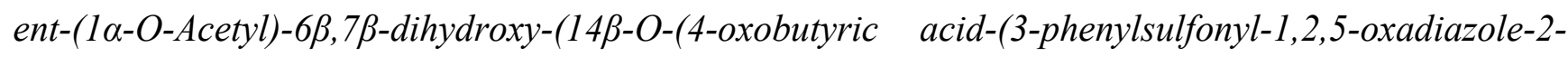
oxide-4)-oxybutyl))-15-oxo-7,20-epoxy-16-kaurene (13c). Yield 48\%, m.p. 109-111 ${ }^{\circ} \mathrm{C}$; IR $v_{\max } 3385$, 2957, 2025, 1737, 1616, 1554, 1451, 1371, 733, $686 \mathrm{~cm}^{-1} ;{ }^{1} \mathrm{H}-\mathrm{NMR}\left(\mathrm{CDCl}_{3}\right), \delta$ (ppm) $1.12(6 \mathrm{H}, \mathrm{s}$, $\left.-\mathrm{CH}_{3}\right), 1.99\left(3 \mathrm{H}, \mathrm{s}, \mathrm{CH}_{3}\right), 3.13(1 \mathrm{H}, \mathrm{d}, J=9.6 \mathrm{~Hz}, 13-\mathrm{CH}), 3.78(1 \mathrm{H}, \mathrm{m}, 6-\mathrm{CH}), 4.19\left(2 \mathrm{H}, \mathrm{m},-\mathrm{CH}_{2}\right)$, $4.11,4.27\left(\right.$ each $\left.1 \mathrm{H}, \mathrm{dd}, J_{\mathrm{A}}=J_{\mathrm{B}}=10.5 \mathrm{~Hz}, 20-\mathrm{CH}_{2}\right), 4.46\left(2 \mathrm{H}, \mathrm{t}, J=7.5 \mathrm{~Hz},-\mathrm{CH}_{2}\right), 4.62(1 \mathrm{H}, \mathrm{m}$, $1-\mathrm{CH}), 5.53\left(1 \mathrm{H}, \mathrm{s}, 17-\mathrm{CH}_{2}\right), 5.88(1 \mathrm{H}, \mathrm{s}, 14-\mathrm{CH}), 6.11(1 \mathrm{H}, \mathrm{d}, J=10.5 \mathrm{~Hz}, 6-\mathrm{OH}), 6.16(1 \mathrm{H}, \mathrm{s}$, 17- $\left.\mathrm{CH}_{2}\right), 7.64(2 \mathrm{H}, \mathrm{t}, J=7.5 \mathrm{~Hz}, \mathrm{Ar}-\mathrm{H}), 7.78(1 \mathrm{H}, \mathrm{t}, J=7.2 \mathrm{~Hz}, \mathrm{Ar}-\mathrm{H}), 8.07(2 \mathrm{H}, \mathrm{d}, J=7.8 \mathrm{~Hz}$, Ar-H); MS(ESI) $m / z: 820.4\left[\mathrm{M}+\mathrm{NH}_{4}\right]^{+}, 803.3[\mathrm{M}+\mathrm{H}]^{+}, 837.3[\mathrm{M}+\mathrm{Cl}]^{-}$; HR-MS (ESI, M+Na) $m / z$ : calcd for $\mathrm{C}_{38} \mathrm{H}_{46} \mathrm{~N}_{2} \mathrm{NaO}_{15} \mathrm{~S}$ : 825.2511, found 825.2525.

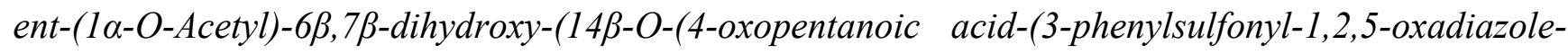
2-oxide-4)-oxyethyl))-15-oxo-7,20-epoxy-16-kaurene (13d). Yield 42\%, m.p. 92-94 ${ }^{\circ} \mathrm{C}$; IR $v_{\max } 3530$, 3386, 2956, 2025, 1738, 1618, 1553, 1451, 731, $686 \mathrm{~cm}^{-1} ;{ }^{1} \mathrm{H}-\mathrm{NMR}\left(\mathrm{CDCl}_{3}\right), \delta$ (ppm) $1.12(6 \mathrm{H}, \mathrm{s}$, $\left.\mathrm{CH}_{3}\right), 1.99\left(3 \mathrm{H}, \mathrm{s},-\mathrm{CH}_{3}\right), 3.16(1 \mathrm{H}, \mathrm{d}, J=9.9 \mathrm{~Hz}, 13-\mathrm{CH}), 3.75(1 \mathrm{H}, \mathrm{m}, 6-\mathrm{CH}), 4.17,4.27$ (each 1H, $\left.\mathrm{dd}, J_{\mathrm{A}}=J_{\mathrm{B}}=10.5 \mathrm{~Hz}, 20-\mathrm{CH}_{2}\right), 4.49\left(2 \mathrm{H}, \mathrm{m},-\mathrm{CH}_{2}\right), 4.61\left(2 \mathrm{H}, \mathrm{m},-\mathrm{CH}_{2}\right), 5.50\left(1 \mathrm{H}, \mathrm{s}, 17-\mathrm{CH}_{2}\right), 5.83$ $(1 \mathrm{H}, \mathrm{s}, 14-\mathrm{CH}), 6.06(1 \mathrm{H}, \mathrm{d}, J=9.6 \mathrm{~Hz}, 6-\mathrm{OH}), 6.13\left(1 \mathrm{H}, \mathrm{s}, 17-\mathrm{CH}_{2}\right), 7.63(2 \mathrm{H}, \mathrm{t}, J=7.8 \mathrm{~Hz}, \mathrm{Ar}-\mathrm{H})$, $7.76(1 \mathrm{H}, \mathrm{t}, J=7.5 \mathrm{~Hz}, \mathrm{Ar}-\mathrm{H}), 8.06(2 \mathrm{H}, \mathrm{d}, J=7.5 \mathrm{~Hz}, \mathrm{Ar}-\mathrm{H})$; MS(ESI) $m / z: 806.4\left[\mathrm{M}+\mathrm{NH}_{4}\right]^{+}, 789.2$ $[\mathrm{M}+\mathrm{H}]^{+}, 823.3[\mathrm{M}+\mathrm{Cl}]^{-}$; HR-MS (ESI, $\left.\mathrm{M}+\mathrm{Na}\right) \mathrm{m} / \mathrm{z}$ : calcd for $\mathrm{C}_{37} \mathrm{H}_{44} \mathrm{~N}_{2} \mathrm{NaO}_{15} \mathrm{~S}$ : 811.2355 , found 811.2367 .

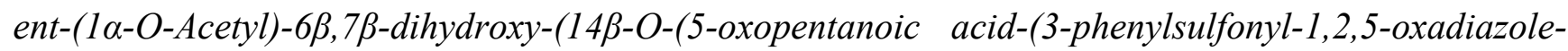
2-oxide-4)-oxypropyl))-15-oxo-7,20-epoxy-16-kaurene (13e). Yield 36\%, m.p. 86-88 ${ }^{\circ} \mathrm{C}$; IR $v_{\max } 3421$, 2958, 2025, 1737, 1616, 1554, 1452, 1374, 732, $686 \mathrm{~cm}^{-1} ;{ }^{1} \mathrm{H}-\mathrm{NMR}\left(\mathrm{CDCl}_{3}\right), \delta(\mathrm{ppm}) 1.12(6 \mathrm{H}, \mathrm{s}$, 
$\left.-\mathrm{CH}_{3}\right), 2.19\left(3 \mathrm{H}, \mathrm{s},-\mathrm{CH}_{3}\right), 3.16(1 \mathrm{H}, \mathrm{d}, J=10.2 \mathrm{~Hz}, 13-\mathrm{CH}), 3.77(1 \mathrm{H}, \mathrm{m}, 6-\mathrm{CH}), 4.20,4.38$ (each $\left.1 \mathrm{H}, \mathrm{dd}, J_{\mathrm{A}}=J_{\mathrm{B}}=10.5 \mathrm{~Hz}, 20-\mathrm{CH}_{2}\right), 4.26\left(2 \mathrm{H}, \mathrm{t}, J=6.0 \mathrm{~Hz},-\mathrm{CH}_{2}\right), 4.50\left(2 \mathrm{H}, \mathrm{t}, J=6.0 \mathrm{~Hz},-\mathrm{CH}_{2}\right)$, $4.62(1 \mathrm{H}, \mathrm{m}, 1-\mathrm{CH}), 5.52(1 \mathrm{H}, \mathrm{s}, 14-\mathrm{CH}), 5.83\left(1 \mathrm{H}, \mathrm{s}, 17-\mathrm{CH}_{2}\right), 6.06(1 \mathrm{H}, \mathrm{d}, J=10.5 \mathrm{~Hz}, 6-\mathrm{OH}), 6.15$ $\left(1 \mathrm{H}, \mathrm{s}, 17-\mathrm{CH}_{2}\right), 7.63(2 \mathrm{H}, \mathrm{t}, J=7.5 \mathrm{~Hz}, \mathrm{Ar}-\mathrm{H}), 7.77(1 \mathrm{H}, \mathrm{t}, J=7.2 \mathrm{~Hz}, \mathrm{Ar}-\mathrm{H}), 8.06(2 \mathrm{H}, \mathrm{d}$, $J=7.5 \mathrm{~Hz}, \mathrm{Ar}-\mathrm{H}$ ); MS(ESI) $m / z: 803.3[\mathrm{M}+\mathrm{H}]^{+}, 837.4[\mathrm{M}+\mathrm{Cl}]^{-}$; HR-MS (ESI, M+Na) $m / z$ : calcd for $\mathrm{C}_{38} \mathrm{H}_{46} \mathrm{~N}_{2} \mathrm{NaO}_{15} \mathrm{~S}: 825.2511$, found 825.2523.

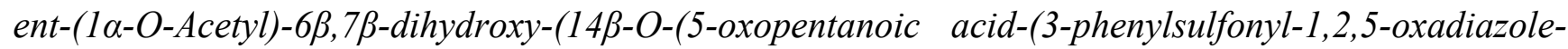
2-oxide-4)-oxybutyl))-15-oxo-7,20-epoxy-16-kaurene (13f). Yield 40\%, m.p. 98-101 ${ }^{\circ} \mathrm{C}$; IR $v_{\max } 3394$, 2957, 2025, 1737, 1617, 1554, 1451, 1373, 732, $686 \mathrm{~cm}^{-1} ;{ }^{1} \mathrm{H}-\mathrm{NMR}\left(\mathrm{CDCl}_{3}\right), \delta$ (ppm) $1.12(6 \mathrm{H}, \mathrm{s}$, $\left.-\mathrm{CH}_{3}\right), 2.35\left(3 \mathrm{H}, \mathrm{s},-\mathrm{CH}_{3}\right), 3.17(1 \mathrm{H}, \mathrm{d}, J=9.3 \mathrm{~Hz}, 13-\mathrm{CH}), 3.76(1 \mathrm{H}, \mathrm{m}, 6-\mathrm{CH}), 4.20(2 \mathrm{H}, \mathrm{t}, J=6.0 \mathrm{~Hz}$, $\left.-\mathrm{CH}_{2}\right), 4.18,4.27\left(\right.$ each $\left.1 \mathrm{H}, \mathrm{dd}, J_{\mathrm{A}}=J_{\mathrm{B}}=10.2 \mathrm{~Hz}, 20-\mathrm{CH}_{2}\right), 4.46\left(2 \mathrm{H}, \mathrm{t}, J=5.7 \mathrm{~Hz},-\mathrm{CH}_{2}\right), 4.61(1 \mathrm{H}$, m, 1-CH), $5.52\left(1 \mathrm{H}, \mathrm{s}, 17-\mathrm{CH}_{2}\right), 5.83(1 \mathrm{H}, \mathrm{s}, 14-\mathrm{CH}), 6.07(1 \mathrm{H}, \mathrm{d}, J=10.2 \mathrm{~Hz}, 6-\mathrm{OH}), 6.15(1 \mathrm{H}, \mathrm{s}$, 17- $\left.\mathrm{CH}_{2}\right), 7.63(2 \mathrm{H}, \mathrm{t}, J=7.2 \mathrm{~Hz}, \mathrm{Ar}-\mathrm{H}), 7.74(1 \mathrm{H}, \mathrm{t}, J=7.8 \mathrm{~Hz}, \mathrm{Ar}-\mathrm{H}), 8.05(2 \mathrm{H}, \mathrm{d}, J=7.2 \mathrm{~Hz}$, Ar-H); MS(ESI) $m / z: 834.4\left[\mathrm{M}+\mathrm{NH}_{4}\right]^{+}, 817.3[\mathrm{M}+\mathrm{H}]^{+}, 851.3[\mathrm{M}+\mathrm{Cl}]^{-}$; HR-MS (ESI, M+Na) $m / z$ : calcd for $\mathrm{C}_{39} \mathrm{H}_{48} \mathrm{~N}_{2} \mathrm{NaO}_{15} \mathrm{~S}$ : 839.2668, found 839.2679.

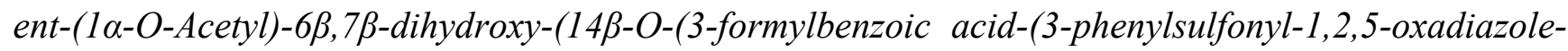
2-oxide-4)-oxyethyl))-15-oxo-7,20-epoxy-16-kaurene (13g). Yield $46 \%$, m.p. $154-156{ }^{\circ} \mathrm{C}$; IR $v_{\max }$ 3383, 2957, 2025, 1736, 1617, 1554, 1451, 1364, 739, $685 \mathrm{~cm}^{-1} ;{ }^{1} \mathrm{H}-\mathrm{NMR}\left(\mathrm{CDCl}_{3}\right), \delta(\mathrm{ppm}) 1.12(6 \mathrm{H}$, $\left.\mathrm{s},-\mathrm{CH}_{3}\right), 2.01\left(3 \mathrm{H}, \mathrm{s}, \mathrm{CH}_{3}\right), 3.36(1 \mathrm{H}, \mathrm{d}, J=9.6 \mathrm{~Hz}, 13-\mathrm{CH}), 3.75(1 \mathrm{H}, \mathrm{m}, 6-\mathrm{CH}), 4.19,4.36$ (each 1H, $\left.\mathrm{dd}, J_{\mathrm{A}}=J_{\mathrm{B}}=10.5 \mathrm{~Hz}, 20-\mathrm{CH}_{2}\right), 4.64\left(2 \mathrm{H}, \mathrm{m},-\mathrm{CH}_{2}\right), 4.79\left(2 \mathrm{H}, \mathrm{m},-\mathrm{CH}_{2}\right), 4.82(1 \mathrm{H}, \mathrm{m}, 1-\mathrm{CH}), 5.54$ $\left(1 \mathrm{H}, \mathrm{s}, 17-\mathrm{CH}_{2}\right), 6.02(1 \mathrm{H}, \mathrm{s}, 14-\mathrm{CH}), 6.03(1 \mathrm{H}, \mathrm{d}, J=10.5 \mathrm{~Hz}, 6-\mathrm{OH}), 6.15\left(1 \mathrm{H}, \mathrm{s}, 17-\mathrm{CH}_{2}\right), 7.44$ $(2 \mathrm{H}, \mathrm{t}, J=7.5 \mathrm{~Hz}, \mathrm{Ar}-\mathrm{H}), 7.79(1 \mathrm{H}, \mathrm{m}, \mathrm{Ar}-\mathrm{H}), 7.58(4 \mathrm{H}, \mathrm{m}, \mathrm{Ar}-\mathrm{H}), 8.03(2 \mathrm{H}, \mathrm{d}, J=7.8 \mathrm{~Hz}$, Ar-H); MS(ESI) $m / z: 840.2\left[\mathrm{M}+\mathrm{NH}_{4}\right]^{+}, 823.2[\mathrm{M}+\mathrm{H}]^{+}, 857.3[\mathrm{M}+\mathrm{Cl}]^{-}$; HR-MS (ESI, M+Na) $m / z$ : calcd for $\mathrm{C}_{40} \mathrm{H}_{42} \mathrm{~N}_{2} \mathrm{NaO}_{15} \mathrm{~S}$ : 845.2198, found 845.2208.

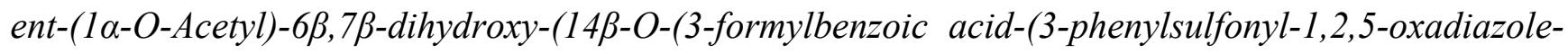
2-oxide-4)-oxypropyl))-15-oxo-7,20-epoxy-16-kaurene (13h). Yield 52\%, m.p. 136-138 ${ }^{\circ} \mathrm{C}$; IR $v_{\max }$ 3379, 2957, 2025, 1735, 1616, 1554, 1451, 1374, 738, $685 \mathrm{~cm}^{-1} ;{ }^{1} \mathrm{H}-\mathrm{NMR}\left(\mathrm{CDCl}_{3}\right), \delta(\mathrm{ppm}) 1.12(6 \mathrm{H}$, $\left.\mathrm{s},-\mathrm{CH}_{3}\right), 2.02\left(3 \mathrm{H}, \mathrm{s},-\mathrm{CH}_{3}\right), 3.33(1 \mathrm{H}, \mathrm{d}, J=9.6 \mathrm{~Hz}, 13-\mathrm{CH}), 3.78(1 \mathrm{H}, \mathrm{m}, 6-\mathrm{CH}), 4.22,4.34$ (each $\left.1 \mathrm{H}, \mathrm{dd}, J_{\mathrm{A}}=J_{\mathrm{B}}=8.7 \mathrm{~Hz}, 20-\mathrm{CH}_{2}\right), 4.45\left(1 \mathrm{H}, \mathrm{m},-\mathrm{CH}_{2}\right), 4.57\left(1 \mathrm{H}, \mathrm{m},-\mathrm{CH}_{2}\right), 4.61\left(2 \mathrm{H}, \mathrm{m},-\mathrm{CH}_{2}\right), 4.64$ $(1 \mathrm{H}, \mathrm{m}, 1-\mathrm{CH}), 5.56\left(1 \mathrm{H}, \mathrm{s}, 17-\mathrm{CH}_{2}\right), 6.02(1 \mathrm{H}, \mathrm{s}, 14-\mathrm{CH}), 6.10(1 \mathrm{H}, \mathrm{d}, J=10.5 \mathrm{~Hz}, 6-\mathrm{OH}), 6.17(1 \mathrm{H}$, s, 17- $\left.\mathrm{CH}_{2}\right), 7.53(2 \mathrm{H}, \mathrm{m}, \mathrm{Ar}-\mathrm{H}), 7.62(3 \mathrm{H}, \mathrm{m}, \mathrm{Ar}-\mathrm{H}), 7.72(2 \mathrm{H}, \mathrm{m}, \mathrm{Ar}-\mathrm{H}), 8.09(2 \mathrm{H}, \mathrm{d}, J=7.8 \mathrm{~Hz}$, Ar-H); MS(ESI) $m / z: 854.3\left[\mathrm{M}+\mathrm{NH}_{4}\right]^{+}, 837.2[\mathrm{M}+\mathrm{H}]^{+}, 871.3[\mathrm{M}+\mathrm{Cl}]^{-}$; HR-MS (ESI, M+Na) $m / z$ : calcd for $\mathrm{C}_{41} \mathrm{H}_{44} \mathrm{~N}_{2} \mathrm{NaO}_{15} \mathrm{~S}$ : 859.2355 , found 859.2368 .

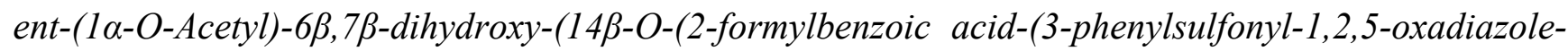
2-oxide-4)-oxybutyl))-15-oxo-7,20-epoxy-16-kaurene (13i). Yield $45 \%$, m.p. $116-118{ }^{\circ} \mathrm{C}$; IR $v_{\max }$ 3382, 2958, 2025, 1726, 1616, 1553, 1451, 1373, 733, $685 \mathrm{~cm}^{-1} ;{ }^{1} \mathrm{H}-\mathrm{NMR}\left(\mathrm{CDCl}_{3}\right), \delta(\mathrm{ppm}) 1.12(6 \mathrm{H}$, $\left.\mathrm{s},-\mathrm{CH}_{3}\right), 1.97\left(3 \mathrm{H}, \mathrm{s},-\mathrm{CH}_{3}\right), 3.45(1 \mathrm{H}, \mathrm{d}, J=9.9 \mathrm{~Hz}, 13-\mathrm{CH}), 3.77(1 \mathrm{H}, \mathrm{m}, 6-\mathrm{CH}), 4.21,4.33$ (each $\left.1 \mathrm{H}, \mathrm{dd}, J_{\mathrm{A}}=J_{\mathrm{B}}=10.5 \mathrm{~Hz}, 20-\mathrm{CH}_{2}\right), 4.43\left(2 \mathrm{H}, \mathrm{m},-\mathrm{CH}_{2}\right), 4.50\left(2 \mathrm{H}, \mathrm{t}, J=5.7 \mathrm{~Hz},-\mathrm{CH}_{2}\right), 4.64(1 \mathrm{H}, \mathrm{m}$, 1-CH), $5.57\left(1 \mathrm{H}, \mathrm{s}, 17-\mathrm{CH}_{2}\right), 6.07(1 \mathrm{H}, \mathrm{s}, 14-\mathrm{CH}), 6.07(1 \mathrm{H}, \mathrm{d}, J=10.2 \mathrm{~Hz}, 6-\mathrm{OH}), 6.16(1 \mathrm{H}, \mathrm{s}$, 
17- $\left.\mathrm{CH}_{2}\right), 7.54(3 \mathrm{H}, \mathrm{m}, \mathrm{Ar}-\mathrm{H}), 7.61(2 \mathrm{H}, \mathrm{t}, J=7.8 \mathrm{~Hz}, \mathrm{Ar}-\mathrm{H}), 7.77(2 \mathrm{H}, \mathrm{m}, \mathrm{Ar}-\mathrm{H}), 8.06(2 \mathrm{H}, \mathrm{d}, J=7.2 \mathrm{~Hz}$, Ar-H); MS(ESI) $m / z: 868.3\left[\mathrm{M}+\mathrm{NH}_{4}\right]^{+}, 885.4[\mathrm{M}+\mathrm{Cl}]^{-}$; HR-MS (ESI, M+Na) $m / z$ : calcd for $\mathrm{C}_{42} \mathrm{H}_{46} \mathrm{~N}_{2} \mathrm{NaO}_{15} \mathrm{~S}$ : 873.2511, found 873.2527.

\subsection{In Vitro MTT Assay}

The MTT assay was employed as an in vitro cytotoxicity assay, which was performed in 96-well plates. Test cells at the $\log$ phase of their growth cycle $\left(5 \times 10^{4}\right.$ cell $\left./ \mathrm{mL}\right)$ were added to each well $(100 \mu \mathrm{L} / \mathrm{well})$, then treated in three replicates at various concentrations of the samples $(0.39-100 \mu \mathrm{g} / \mathrm{mL})$, and incubated for $24 \mathrm{~h}$ at $37^{\circ} \mathrm{C}$ in a humidified atmosphere of $5 \% \mathrm{CO}_{2}$. After $72 \mathrm{~h}, 20 \mu \mathrm{L}$ of MTT solution $(5 \mathrm{mg} / \mathrm{mL})$ per well was added to each cultured medium, which was incubated for further $4 \mathrm{~h}$. Then, DMSO was added to each well $(150 \mu \mathrm{L} /$ well $)$. After $10 \mathrm{~min}$ at room temperature, the OD of each well was measured on a Microplate Reader (BIO-RAD instruments Inc. No. 550, Hercules, CA, USA) at a wavelength of $490 \mathrm{~nm}$. In these experiments, the negative reference was $0.1 \%$ DMSO, and taxol was used as the positive reference with the concentration of $10 \mu \mathrm{g} / \mathrm{mL}$.

\subsection{NO-Releasing Test: Nitrate/Nitrite Measurement in Vitro}

The levels of nitrate/nitrite formed from individual compounds were determined by the colorimetric assay using the nitrate/nitrite colorimetric assay kit, in triplicate with $100 \mu \mathrm{M}$ of individual compounds for 0-60 min according to the manufacturer's instructions (Beyotime, Shanghai, China). The lysates were mixed with Griess for $40 \mathrm{~min}$ and centrifugalized for $10 \mathrm{~min}$, and then followed by measuring at $540 \mathrm{~nm}$, similar as previously reported [13-17].

\section{Conclusions}

In summary, a series of novel furoxan/oridonin hybrids were synthesized and tested for antiproliferative activity against four human cancer cell lines by an in vitro MTT assay. Among them, compound 9h exhibited the most potential anti-tumor activity against all test cell lines. The preliminary SAR of the target compounds was discussed based on the experimental data obtained. Furthermore, more than $15 \mu \mathrm{mol} / \mathrm{L}$ NO were produced by all target compounds at the 60 min time point, and the results showed that higher levels of NO releasing produced stronger anti-proliferative activity, so high levels of NO release by these hybrids could play a role in growth inhibition activity. These results suggested that NO-donor/natural product hybrids may provide a promising approach for the discovery of novel anti-tumor agents. Further studies on the structure modification of these hybrids and the mechanism of the derivatives are currently in progress and will be reported in due course.

\section{Acknowledgments}

This study was supported by grant from National Natural Science Fund (No. 30973610), Key Fund of Ministry of Education of China (No. 108069), Specialized Research Fund for the Doctoral Program of Higher Education (No. 20100096110001), Project for Research and Innovation of Graduates in Universities of Jiangsu Province (CXZZ11-0800) and the Fundamental Research Funds for the Central Universities (JKY2011030) for financial assistance. 


\section{References and Notes}

1. Mocellin, S. Nitric oxide: Cancer target or anticancer agent? Curr. Cancer Drug Targets 2009, 9, 214-236.

2. Ignarro, L.J. Signal transduction mechanisms involving nitric oxide. Biochem. Pharmacol. 1991, 41, 485-490.

3. Fukuto, J.M.; Wink, D.A. Nitric oxide (NO): Formation and biological roles in mammalian systems. Met. Ions Biol. Syst. 1999, 36, 547-595.

4. Wink, D.A.; Ridnour, L.A.; Hussain, S.P.; Harris, C.C. The reemergence of nitric oxide and cancer. Nitric Oxide 2008, 19, 65-67.

5. Hirst, D.; Robson, T. Nitric oxide in cancer therapeutics: Interaction with cytotoxic chemotherapy. Curr. Pharm. Des. 2010, 16, 411-420.

6. Millet, A.; Bettaieb, A.; Renaud, F.; Prevotat, L.; Hammann, A.; Solary, E.; Mignotte, B.; Jeannin, J.F. Influence of the nitric oxide donor glyceryl trinitrate on apoptotic pathways in human colon cancer cells. Gastroenterology 2002, 123, 235-246.

7. Postovit, L.M.; Adams, M.A.; Lash, G.E.; Heaton, J.P.; Graham, C.H. Nitric oxide-mediated regulation of hypoxia-induced B16F10 melanoma metastasis. Int. J. Cancer 2004, 108, 47-53.

8. Findlay, V.J.; Townsend, D.M.; Saavedra, J.E.; Buzard, G.S.; Citro, M.L.; Keefer, L.K.; Ji, X.; Tew, K.D. Tumor cell responses to a novel glutathione S-transferase-activated nitric oxidereleasing prodrug. Mol. Pharmacol. 2004, 65, 1070-1079.

9. Yasuda, H.; Yamaya, M.; Nakayama, K.; Sasaki, T.; Ebihara, H.; Kanda, A.; Asada, M.; Inoue, D.; Suzuki, T.; Okazaki, T.; et al. Randomized phase II trial comparing nitroglycerin plus vinorelbine and cisplatin with vinorelbine and cisplatin alone in previously untreated stage IIIB/IV non-smallcell lung cancer. J. Clin. Oncol. 2006, 24, 688-694.

10. Siemens, D.R.; Heaton, J.P.; Adams, M.A.; Kawakami, J.; Graham, C.H. Phase II study of nitric oxide donor for men with increasing prostate-specific antigen level after surgery or radiotherapy for prostate cancer. Urology 2009, 74, 878-883.

11. Moharram, S.; Zhou, A.; Wiebe, L.I.; Knaus, E.E. Design and synthesis of 3'- and 5'-O-(3benzenesulfonylfuroxan-4-yl)-2'-deoxyuridines: Biological evaluation as hybrid nitric oxide donor-nucleoside anticancer agents. J. Med. Chem. 2004, 47, 1840-1846.

12. Maksimovic-Ivanic, D.; Mijatovic, S.; Harhaji, L.; Miljkovic, D.; Dabideen, D.; Fan Cheng, K.; Mangano, K.; Malaponte, G.; Al-Abed, Y.; Libra, M.; et al. Anticancer properties of the novel nitric oxide-donating compound (S,R)-3-phenyl-4,5-dihydro-5-isoxazole acetic acid-nitric oxide in vitro and in vivo. Mol. Cancer Ther. 2008, 7, 510-520.

13. Chen, L.; Zhang, Y.; Kong, X.; Lan, E.; Huang, Z.; Peng, S.; Kaufman, D.L.; Tian, J. Design, synthesis, and antihepatocellular carcinoma activity of nitric oxide releasing derivatives of oleanolic acid. J. Med. Chem. 2008, 51, 4834-4838.

14. Lai, Y.; Shen, L.; Zhang, Z.; Liu, W.; Zhang, Y.; Ji, H.; Tian, J. Synthesis and biological evaluation of furoxan-based nitric oxide-releasing derivatives of glycyrrhetinic acid as antihepatocellular carcinoma agents. Bioorg. Med. Chem. Lett. 2010, 20, 6416-6420. 
15. Ling, Y.; Ye, X.; Ji, H.; Zhang, Y.; Lai, Y.; Peng, S.; Tian, J. Synthesis and evaluation of nitric oxide-releasing derivatives of farnesylthiosalicylic acid as anti-tumor agents. Bioorg. Med. Chem. 2010, 18, 3448-3456.

16. Ling, Y.; Ye, X.; Zhang, Z.; Zhang, Y.; Lai, Y.; Ji, H.; Peng, S.; Tian, J. Novel nitric oxidereleasing derivatives of farnesylthiosalicylic acid: Synthesis and evaluation of antihepatocellular carcinoma activity. J. Med. Chem. 2011, 54, 3251-3259.

17. Tang, X.; Gu, X.; Ai, H.; Wang, G.; Peng, H.; Lai, Y.; Zhang, Y. Synthesis and evaluation of nitric oxide-releasing DDB derivatives as potential Pgp-mediated MDR reversal agents in MCF-7/Adr cells. Bioorg. Med. Chem. Lett. 2012, 22, 801-805.

18. Kang, N.; Zhang, J.H.; Qiu, F.; Chen, S.; Tashiro, S.; Onodera, S.; Ikejima, T. Induction of G(2)/M phase arrest and apoptosis by oridonin in human laryngeal carcinoma cells. J. Nat. Prod. 2010, 73, 1058-1063.

19. Xu, J.; Yang, J.; Ran, Q.; Wang, L.; Liu, J.; Wang, Z.; Wu, X.; Hua, W.; Yuan, S.; Zhang, L.; et al. Synthesis and biological evaluation of novel 1-O- and 14-O-derivatives of oridonin as potential anticancer drug candidates. Bioorg. Med. Chem. Lett. 2008, 18, 4741-4744.

20. Wang, L.; Ran, Q.; Li, D.; Yao, H.; Zhang, Y.; Yuan, S.; Zhang, L.; Shen, M.; Xu, J. Synthesis and anti-tumor activity of 14-O-derivatives of natural oridonin. Chin. J. Nat. Med. 2011, 9, 194-198.

21. Wang, L.; Li, D.; Wang, C.; Zhang, Y.; Xu, J. Recent progress in the development of natural ent-kaurane diterpenoids with anti-tumor activity. Mini-Rev. Med. Chem. 2011, 11, 910-919.

22. Wang, L.; Li, D.; Xu, S.; Cai, H.; Yao, H.; Zhang, Y.; Jiang, J.; Xu, J. The conversion of oridonin to spirolactone-type or enmein-type diterpenoid: Synthesis and biological evaluation of ent-6,7-seco-oridonin derivatives as novel potential anticancer agents. Eur. J. Med. Chem. 2012, $52,242-250$.

Sample Availability: Contact the first authors.

(C) 2012 by the authors; licensee MDPI, Basel, Switzerland. This article is an open access article distributed under the terms and conditions of the Creative Commons Attribution license (http://creativecommons.org/licenses/by/3.0/). 